Original Contribution

\title{
ANAL YSIS OF THE COMMON AGRICULTURAL POLICY FINANCIAL SUBSIDIES IMPACT IN ALL EU COUNTRIES
}

\author{
N. Galluzzo* \\ Association of Geographical and Economic Studies of Rural Areas (ASGEAR), Rieti, Italy
}

\begin{abstract}
This study has investigated by a quantitative approach the impact of financial subsidies allocated by the Common Agricultural Policy to European farms; the aim was to assess also the linkages among financial supports allocated by the Common Agricultural Policy and rural development by proposing a briefly definition of a rurality index.

METHODS: In this research, it has used two quantitative approaches as the Self-Organizing Maps and the Partial Least Square Structural Equation Model (PLS-SEM) over two different years such as 2007 and 2017 in a sample of farms belonging to the Farm Accountancy Data Network dataset.

RESULTS: Findings have emphasized the impact and the main role of financial subsidies in stimulating rural growth even if there are also lots of unbalances between EU states.

CONCLUSIONS: The role of the public administrations at a local level should be addressed towards a strictly severe task to condense main priorities of rural development and the needs of the rural population in specific and pilot initiatives.
\end{abstract}

Key words: Kohonen's maps, Partial Least Square Structural Equation Model, second pillar, rural areas.

\section{INTRODUCTION}

Since the foundation of the Common Agricultural Policy the main targets have been to support farmers by higher prices of agcommodities than international context (1-5). The main negative consequence of this excess ag-commodities production was to increase the financial budget towards farms at the expense of other economic and productive sectors stimulating in the public opinion a growing criticism to the Common Agricultural Policy. As a consequence of the awareness of two tightly linked concepts as the rural development and rural areas as well emphasized by the Cork Conference the European Union in the frame of the Rural Development Programme has subsidized by the Common Agricultural Policy rural areas able to produce positive externalities reducing in the same time the socio-economic marginalization in these territories $(1,4,6)$.

\footnotetext{
*Correspondence to: Nicola Galluzzo, Association of Geographical and Economic Studies of Rural Areas (ASGEAR), Via Salaria per L'Aquila, 76 scalaA,02100 Rieti-Italy,email: asgear@libero.it
}

As a consequence of the economic and management bottlenecks in a perspective of international trade and agreements, the European Commission has undergone the Common Agricultural Policy to crucial and complete significant transformations which comes under the framework of the development of a new integrated model of agrarian specialization and a more sensitive behaviour in urban citizens towards farmers, who are able to produce positive or negative externalities in the transition phase from a productivist model to a post productivist one based also on the multifunctionality $(1,2,7)$. As argued by lots of scholars, farmers become dwellers and active agents of an endogenous cohesive and bottom-up rural process of socioeconomic development able to increase the level of involvement of rural communities in local development which are processes of local growth aimed at lessening socio-economic exclusion and marginalization as well $(1,8)$.

It is important to underline as the main and priority changes in the Common Agricultural Policy have been radical because it is completely changed under the international 
stimulus and pression proposed by the WTO and other international agreements by a transformation from a commodity-specific policy to a farmer-specific policy (9). The second pillar of the CAP has had the purpose to support by aids and financial subsidies the diversification in rural areas supporting also disadvantaged and stayed behind rural areas at risk of severe depopulation and emigration even if the budged allocated in the Common Agricultural Policy has been significantly lower than the first pillar.

A definition of rurality is very complicated because many are the variables involved in this concept. A literature review in some European countries and in other countries has highlighted as harsh is to find studies and quantitative researches with the purpose to elaborate an index of rurality based on the quantitative estimation of the impact of financial subsidies and other aids to farms allocated by the first and second pillar of the Common Agricultural Policy (2, 3, 10-15). Halfacree in 1993 has argued as the lack in defining an index of rurality is due to a specific and complete definition of rural and rurality, liked also to its interpretation, because of different variables are involved in the process of explanation of the meaning of rurality and it is not easy to assess the main cause-effect relationships.

The first definition of a rural index has been proposed in 1977 by Cloke (15). This author has defined a pivotal guideline in investigating rural areas giving a holistic and complete definition of what can be defined as rural in a methodological and theoretical framework (2, $3,10-14)$. These authors have underlined as the concept of rural is useful in setting up lots of specific strategic actions to the countryside in an integrated and cohesive perspective. If the main target of the researchers is to assess the impact of the financial subsidies allocated by the Common Agricultural Policy the index of rurality can be considered quite adequate to this target. In fact, the index of rurality in a quantitative perspective is good enough in assessing which socio-economic variables have been involved able to explain if there is an effect on the socio-economic development in rural areas $(2,3,10)$. The index of rurality is adequate in describing a different allocation of specific financial resources linked to other socio-economic variables aimed at reducing the marginalization in rural areas $(2,3,10)$.

\section{AIM OF THE RESEARCH}

GALLUZZO N.

Considering the different enlargements of the European Union occurred in 2004 (Poland, Slovenia, Cyprus, Czech Republic, Estonia, Latvia Lithuania, Slovakia), in 2007 (Bulgaria and Romania) and in 2013 (Croatia), the core purpose of this research was to investigated by a quantitative approach the impact of financial subsidies allocated by the Common Agricultural Policy in all European Union countries. Still, another aim of this study was to assess in depth which variables have affected the rurality, hence an index of rurality can be very useful in addressing some actions and financial measures in the agricultural policy framework towards rural territories. In order to assess quantitatively the effects and impacts of the CAP financial subsidies, in this paper, it has used as a source of data a sample of European farms part of the dataset published by the Farm Accountancy Data Network from 2004 to 2017.

\section{METHODOLOGY}

The Self Organized Map (SOM) or Kohonen's maps is a non-supervision methodology able to define in a layout of hexagons, made by different neurons, a unique best neuron which is the winner and able to underline some main relationships among all analysed variables, visualizing also in a map the best neuron or winner neuron underlining the main relations among investigated variables as well (16-17). Summing up very briefly the Kohonen's maps are pivotal in emphasizing some main effects generating also a unique winner neuron, which in this study has been represented in the maps by a black hexagon (18). By contrast, white hexagons are the looser neurons located far away from the winner neuron (16-18). In general, Self-Organizing Maps are useful in assessing the structure and the evolution of investigated variables over the time pointing out the best parameter able to summarize different clusters of interactions and similarities in all investigated variables as possible in using other quantitative approaches such as the Principal Component Analysis (19, 20).

Focusing the attention to the SOM it is possible to observe as a map is made by a neural network arranged in grids based on a lower dimension in connections to all neurons of all investigated inputs (16-18). Lucchini et. al. in 2011 have argued as each input is connected to other neurons of the output by a weight vector able to define the position of a 
GALLUZZO N.

centroid in the space (21). The neuron with the weight vector the closest to the stimulus is called Best Matching Unit (BMU) and the intensity of the adjustment decreases in function of the distance of neurons from the BMU and the weight can be assessed in each neuron (Wv) as (16-20):

$\mathrm{Wv}(\mathrm{t}+1)=\mathrm{Wv}(\mathrm{t})+\Theta(\mathrm{v}, \mathrm{t}) \alpha(\mathrm{t})(\mathrm{D}(\mathrm{t})-\mathrm{Wv}(\mathrm{t}))$

$\alpha(t)$ is a decreasing monotonic learning coefficient

$\mathrm{D}(\mathrm{t})$ is the stimulus vector.

As proposed by above mentioned authors, the function for the neighbourhood or distance function $\Theta(v, t)$ depends on the distance in the lattice between the BMU and the neuron $\mathrm{v}$ (1621). In this paper we have used a quantitative approach using the Self Organizing Maps (SOM) proposed by Kohonen utilizing the software Spice_Som.

The assessment of the main correlations and cause effect relationships in the assessment of the rurality index it has used as a source of data the annual survey Farm Accountancy Data Network (FADN), comparing in the different years 2007 and 2017 all farms part of FADN dataset. With the core purpose to estimate the rurality index, it has employed a nonparametric methodology called Partial Least Square Structural Equation Modelling (PLSSEM) able to underline the main direct and indirect cause-effects relationships using the software Smart PLS 3 (22). The PLS-SEM is adequate for research's targets aimed at defining an index of rurality because it fits well with the specific features of the analysis, which are not so common in literature or rather they do not have got consolidated models. Furthermore, the PLS-SEM is adequate to our analysis because of the sample of observation which is modest, a scarcity of theoretical models in literature and also because of theoretical constraints which do not need $a$ priori assumptions $(2,3,10,23-27)$.

The Structural Equation Modelling describes the causality relationships among latent variables by an iterative methodology with the purpose to estimate internal and external correlations in all latent variables using in this research formative relationships among items and latent variables $(2,3,10,23-29)$. The PLSSEM model can be investigated considering the differences between exogenous and endogenous variables, due to the different directions and links among investigated items and latent variables as argued by Monecke and Leisch in 2012 (30):

$$
\mathrm{Y}=\mathrm{YB}+\mathrm{Z}
$$

Summing up, in the equation $\mathrm{Y}$ is the exogenous or endogenous latent variable matrix, $\mathrm{B}$ is a parameter and $\mathrm{Z}$ is the stochastic error which is assumed to be $E[Z]=0(2,3,10$, 30). Furthermore, some elements in the matrix of coefficients B are assumed to be equal to zero when the elements of the adjacency matrix are zero as well (30) and also each latent variable in the PLS model is correlated to the previous latent variable in an interrelated equations system $(24,26,30)$.

Table 1 describes the main endogenous variables investigated in the Partial Lest Square Structural Equation Model in all farms part of the FADN dataset over two-year time 2007 and 2017. Each endogenous variable and also the exogenous variable RURALITY, dummy variable of the index of rurality, has been estimated by different items described shortly in Table 2.

\section{RESULTS AND DISCUSSION}

Considering a non-supervision approach as proposed by the Kohonen in the SelfOrganized Map (SOM), findings in 2007 have pointed out as Spain, Italy and Slovenia have had the best results(black hexagons)taking into account different socio-economic variables such as Usable Agricultural Areas, farm net income, payments to disadvantaged rural areas (LFA payments), total aids paid by the Common Agricultural Policy, decoupled payments disbursed by the first pillar, financial subsidies allocated in the second pillar of the CAP (Figure 1).

Table 1. Description of the main endogenous variable investigated in the PLS-SEM

\begin{tabular}{|l|l|}
\hline \multicolumn{1}{|c|}{ Endogenous variables } & \multicolumn{1}{c|}{ Description } \\
\hline CAP & $\begin{array}{l}\text { Financial subsidies allocated by the first and second pillar of the Common } \\
\text { Agricultural Policy }\end{array}$ \\
\hline Areas & Areas cultivated in hectares in some main crops and animals in farms \\
\hline Income & Farmers income in euro and assets in farms \\
\hline Production & Main yields in some cultivations and breeding animals \\
\hline Cost & Direct costs in each farm \\
\hline
\end{tabular}


Table 2. Description of the main items used in the PLS-SEM

\begin{tabular}{|l|l|}
\hline \multicolumn{1}{|c|}{ Items } & \multicolumn{1}{c|}{ Description } \\
\hline RDP & $\begin{array}{l}\text { Financial subsides in euro allocated by the second pillar of the CAP } \\
\text { to support rural development }\end{array}$ \\
\hline Total_direct_pay & Decoupled payments in euro allocated by the first pillar of the CAP \\
\hline Cereals & Areas in hectares cultivated with cereals \\
\hline Forage_crops & Areas in hectares cultivated with forage \\
\hline Livestock_units & Number of animals \\
\hline Orchards & Areas in hectares with fruit \\
\hline Vegetables_and_flowers & Areas in hectares cultivated with vegetables and fruit \\
\hline Total_assets & Total assets in farms in euro \\
\hline FNI & Farm net income in euro \\
\hline Farm_Net_Value_Added_MEDIAN & Net added value in euro assessed in each farm \\
\hline Feed_livestock_cost & Total costs for animals in euro \\
\hline Fertilisers_cost & Cost for fertilisers in euro \\
\hline Labour_input & Labour cost in euro \\
\hline Seeds_and_plants_costs & Costs for plants and seeds in euro \\
\hline Cereals_y & Yield of cereals \\
\hline Cows_milk_y & Yield in milk \\
\hline Pigmeat_y & Yield in pig meat \\
\hline Sheep_goats & Yield produced by sheep and goats \\
\hline Agritourism & Financial subsidies to farms specialized in agritourism \\
\hline Environmental_subsidies & Financial supports to the environment protection \\
\hline LFA_subsidies & Direct payments to farms located in disadvantaged rural areas \\
\hline
\end{tabular}

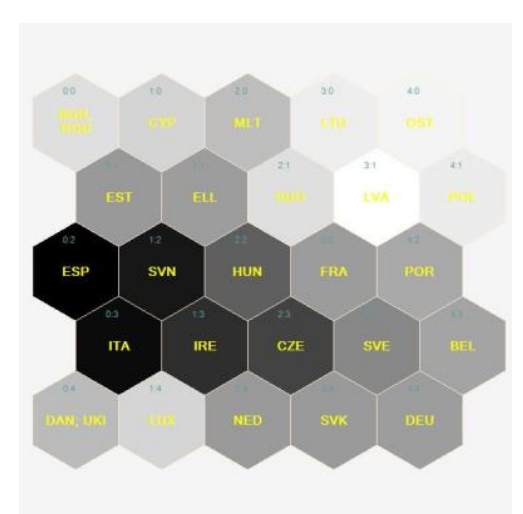

All variables

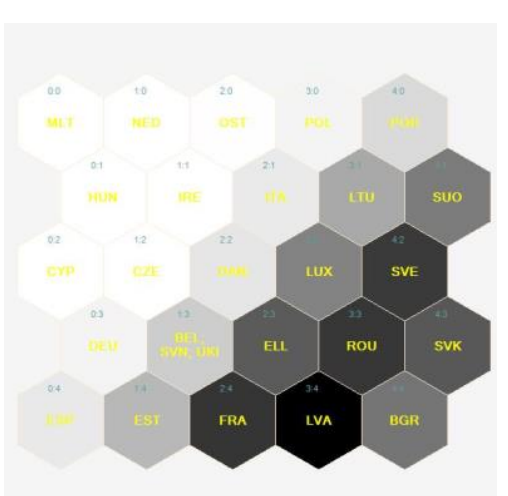

First pillar decoupled payments

Figure 1. Main results in the SOM in the year 2007 in farms part of FADN dataset

Source: elaboration on data https://ec.europa.eu/agriculture/rica/database/database_en.cfm

Addressing the attention to the subsidies allocated by the Rural Development Programme in the second pillar, research's outcomes have underlined as two EU countries such as Germany and Belgium have had the best results in terms of payments allocated by the second pillar. In 2017 the main results of the SOM analysis have pointed out as the best results (black hexagon), considering all variables (Usable Agricultural Areas, farm net income, LFA payments, total aids paid by the
Common Agricultural Policy, decoupled payments disbursed by the first pillar, financial subsidies allocated in the second pillar of the CAP) in two EU countries such as the United Kingdom and Ireland; focusing the attention to the first pillar and to the second pillar financial supports the best results have been respectively found in the Czech Republic, Slovakia and in Spain and Sweden considering only the RDP subsidies paid (Figure 2). 


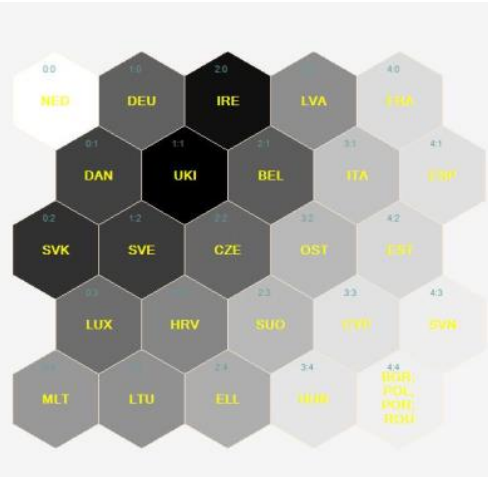

All variables

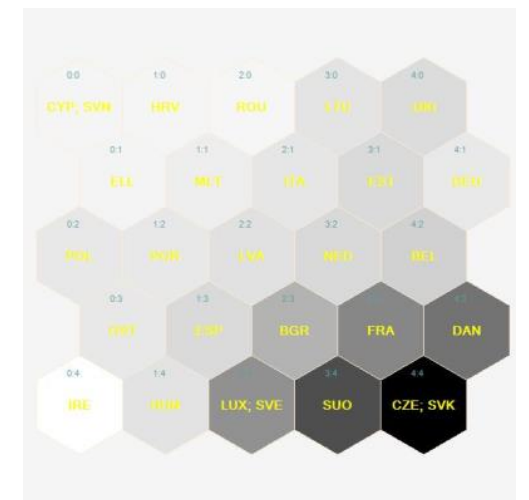

First pillar decoupled payments

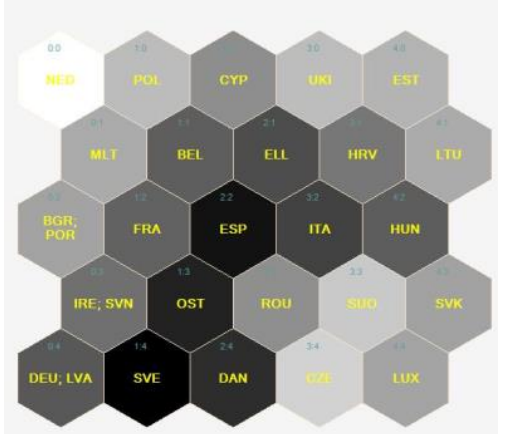

Second pillar subsidies

Figure 2. Main results in the SOM in the year 2017 in farms part of FADN dataset

Source: elaboration on data https://ec.europa.eu/agriculture/rica/database/database_en.cfm

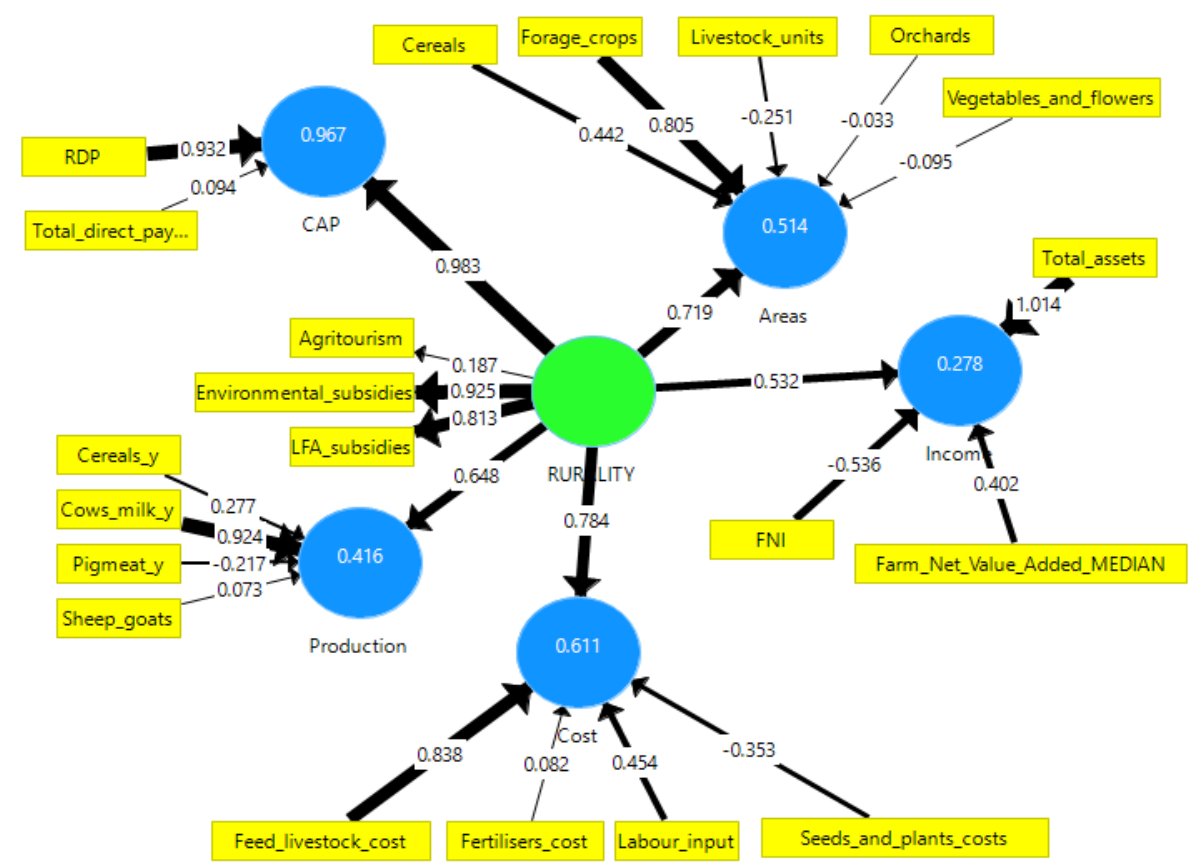

Year 2007

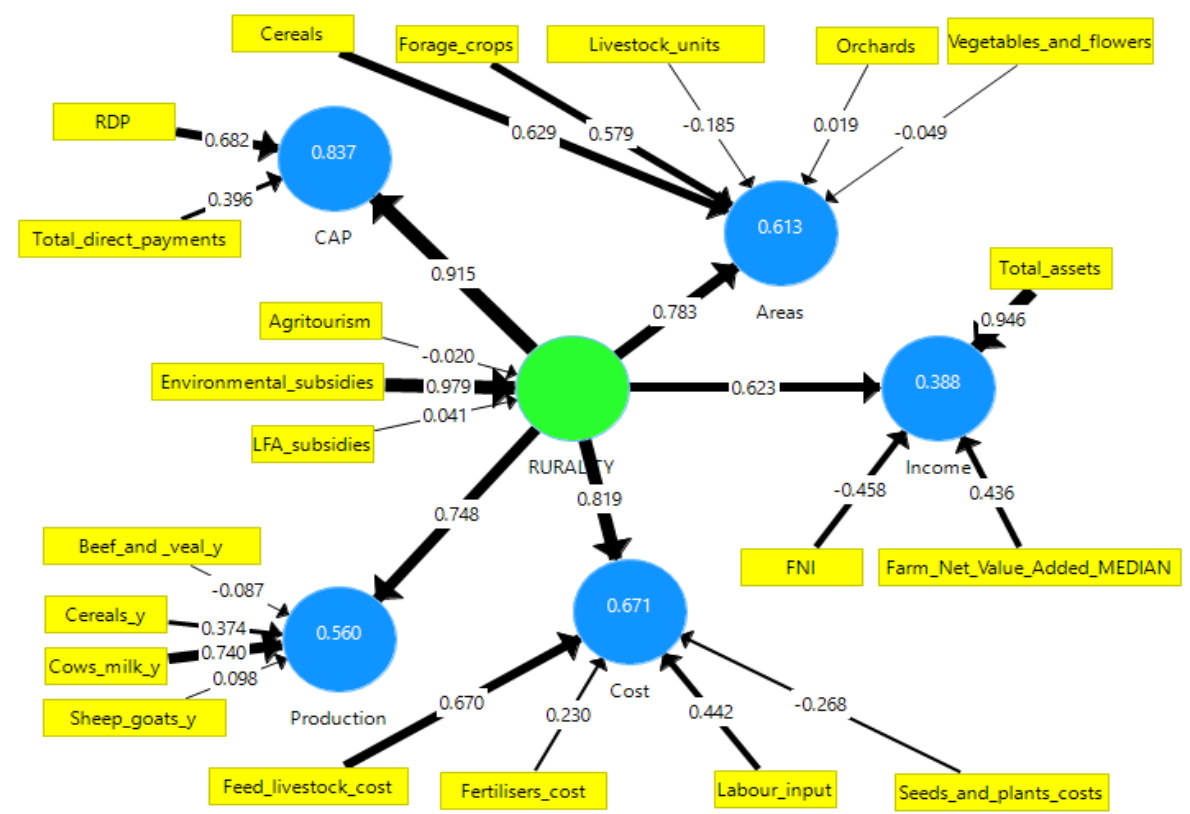

Year 2017

Figure 3. Analysis and index of rurality in 2007 and in 2017 in all farms part of FADN dataset. Source: elaboration on data https://ec.europa.eu/agriculture/rica/database/database_en.cfm 
GALLUZZO N.

The last part of this research has investigated in 2007 and in 2017 the index of rurality, which is a multidimensional latent variable, taking into account all economic variables correlated to the rurality and also able to asses a quantitative index in all farms part of FADN dataset (Figure 3). Comparing two-year times 2007 and in 2017, findings have underlined as the endogenous variable CAP has been able to explain more than 0.80 of the variances in the model even if during the year 2017 there has been a significant increase of the variance examined, in terms of $\mathrm{R}^{2}$, by the endogenous variable Income.

Focusing the attention on the endogenous variable CAP both in 2007 and also in 2017 the item rural development programme has had the highest impact compared to the item total direct payments. The items areas cultivated with cereals and forage have acted directly to the endogenous variable Areas. Summing up, in the two years of observation (2007 and 2017), there has been a growth of the impact of the endogenous variable income to the rurality which has explained as the rurality has a significant connection to the level of farm income.

\section{CONCLUSION}

The effects and impacts of the Common Agricultural Policy have been investigating considering two different quantitative approaches that have corroborated meaningful and noteworthy effects in different European countries of the financial subsidies allocated towards farmers. Some imbalances among countries are a consequence, in particular in new member states belonging to the European Union, of a modest land capital endowment.

Findings have corroborated the main role of financial subsidies allocated by the first pillar than the second in terms of impact on the rurality in all farms part of the FADN dataset. For the future it is important to allocate major financial resources to the second pillar in order to support farmers and in all European areas characterised by a poor level of land capital and a situation of backwardness in skills and technologies.

Drawing some final remarks the role of the public administration should be addressed to a strictly severe task to condense main priorities of rural development in specific and pilot initiatives able to protect the rural space avoiding to drain financial resources from the second pillar of the Common Agricultural Policy at the light of a possible decline in the financial budget of the EU due to the Brexit and other economic constraints which have implied a deep rethinking of the European common policies such as the CAP.

\section{REFERENCES}

1. Galluzzo, N., Technical and economic efficiency analysis on Italian smallholder family farms using Farm Accountancy Data Network dataset. Studies in Agricultural Economics, 117(1): 35-42, 2015.

2. Galluzzo, N., An analysis of rurality index in Romanian countryside by a quantitative approach. Trakia Journal of Sciences, 16(2):134-139, 2018.

3. Galluzzo, N., An assessment of rurality in Italian farms using a quantitative approach. Bulgarian Journal of Agricultural Science, 25(3): 433-438, 2019 a.

4.Vieri, S., Agricoltura: settore multifunzionale allo sviluppo, Edagricole-Il Sole 24ore, Milano, 2012.

5. Van der Ploeg, J.D., Long, A. and Banks, J., Living Countrysides: Rural Development Processes in Europe: the State of the Art. Elsevier EBI, Amsterdam, 2002.

6. Cunha, A., and Swinbank, A., An inside view of the CAP reform process: explaining the MacSharry, Agenda 2000, and Fischler reforms. Oxford University Press, Oxford, 2011.

7. Ilbery, B., Geography of rural change. Routledge, London, 1998.

8. Coble, K.H., Barnett, B.J., and Riley, J.M., Challenging Belief in the Law of Small Numbers (No. 324-2016-11943) presented at the Agricultural \& Applied Economics Association's 2013 Crop Insurance and the Farm Bill Symposium, Louisville, KY, October 8-9, 2013.

9. Beluhova-Uzunova, R., Atanasov, D., and Hristov, K., Analysis of direct payments distribution in Bulgarian agriculture. Trakia Journal of Sciences, 15(1): 282-287, 2017.

10. Galluzzo, N., A socio-economic analysis of rurality in Italy using a PLS-SEM approach. Trakia Journal of Sciences, 17(2): 172-179, $2019 b$.

11. Puia, O.A., The evaluation of rural space through the analysis of the rurality index. Case study: the villages of Sălaj East of Jibou. Forum geographic, 10(2): 264-275, 2011.

12. Halfacree, K.H., Locality and social representation: space, discourse and 
GALLUZZO N.

alternative definitions of the rural. Journal of rural studies, 9(1): 23-37, 1993.

13. Harrington, V., and O'Donoghue, D., Rurality in England and Wales 1991: a replication and extension of the 1981 rurality index. Sociologia Ruralis, 38(2): 178-203, 1998.

14. Olatunde, S., Leduc, E. R., and Berkowitz, J., Different practice patterns of rural and urban general practitioners are predicted by the General Practice Rurality Index. Canadian Journal of Rural Medicine, 12(2): 73-80, 2007.

15. Cloke, P., and Edwards, G., Rurality in England and Wales 1981: a replication of the 1971 index. Regional Studies, 20(4): 289-306, 1986.

16. Galluzzo, N., Analysis of subsidies allocated by the Common Agricultural Policy and cropping specialization in Romanian farms using FADN dataset. Scientific Papers Series Management, Economic Engineering in Agriculture and Rural Development, 16(1): 157-164, $2016 \mathrm{a}$.

17. Galluzzo, N., An analysis of the efficiency in a sample of small Italian farms part of the FADN dataset. Agricultural Economics, 62(2): 62-70, 2016b.

18. Kohonen, T., Self-Organizing Maps Third extended edition, Springer-Verlag, Berlin Heidelberg, 2001.

19. Kaski, S., Kohonen, T., Exploratory data analysis by the self-organizing map: structures of welfare and poverty in the world, In: Refenes, A.P., Yaser, A.M., Weigend A. (Eds), Proceedings of the third international conference on neural networks in the capital markets, World Scientific, 498-507, 1996.

20. Mehmood, Y., Abbas, M., Chen, X., Honkela T. Self-Organizing maps of nutrition, lifestyle and health situation in the World, In: Laaksonen, J., Honkela, T. (eds), Proceedings $8^{\text {th }}$ International Workshop, WSOM 2011, Espoo, Finland, June 13-15 2011, LNCS 6731, SpringerVerlag, p. 160-167, 2011.

21. Lucchini, M., L'analisi dei gruppi, In: De Lillo, A., Argentin, G., Sarti, S., Terraneo,
M. (eds), Analisi multivariata per le scienze sociali, Pearson educational Pearson, Paravia Bruno Mondadori, Torino, 2007.

22. Ringle, M.C., Wende, S. and Becker, J.M., SmartPLS 3. Boenningstedt: SmartPLS $\mathrm{GmbH}$. Retrieved from: http://www.smartpls.com, 2015.

23. Hair, J.F., Sarstedt, M., Ringle, C.M., and Mena, J.A., An assessment of the use of particle least squares structural equation modelling in marketing research. Journal of the Academic Marketing Science, 40: 414433, 2012

24. Hair, J.F., Hollingsworth, C.L., Randolph, A.B. and Chong, A.Y.L. Updated and expanded assessments of PLS-SEM in information systems research. Industrial Management \& Data Systems, 117(3): 442458, 2017.

25. Hair, J.F., Ringle, C.M., and Sarstedt, M., PLS-SEM: Indeed a silver bullet. Journal of Marketing theory and Practice, 19(2): 139152, 2011.

26. Hair, J.F., Hult, G.T.M., Ringle, C. and Sarstedt, M., A primer on partial least squares structural equation modelling (PLSSEM). Sage Publications, Thousand Oaks, 2016.

27. Tenenhaus, M., Amato, S., and Esposito Vinzi, V., A global goodness-of-fit index for PLS structural equation modelling. In: Proceedings of the XLII SIS scientific meeting, 1: 739-742, 2004

28. Wong, K.K.K., Partial least squares structural equation modelling (PLS-SEM) techniques using SmartPLS. Marketing Bulletin, 24(1): 1-32, 2013.

29. Vinzi, V.E., Trinchera, L., and Amato, S., PLS path modelling: from foundations to recent developments and open issues for model assessment and improvement. In: Handbook of partial least squares, Springer, Berlin, 2010.

30. Monecke, A., and Leisch, F., SEM-PLS: structural equation modelling using partial least squares. Journal of Statistic Software, 48(3): 1-32, 2012. 